Check for updates

Cite this: RSC Adv., 2017, 7, 45113

Received 28th June 2017

Accepted 5th September 2017

DOI: $10.1039 / c 7 r a 07169 h$

rsc.li/rsc-advances

\section{G0.5 PAMAM dendrimers improve the kinetic stabilization and nanoscale precipitation mechanism of amorphous calcium carbonate $\uparrow$}

\author{
Weiguang Shi, (D) ${ }^{a}$ Zaiqiang Ma, ${ }^{a}$ Yuqiang $\mathrm{Mu}^{a}$ Jun Wang, ${ }^{\text {*a }}$ Benxian $\mathrm{Li}^{\mathrm{b}}$ \\ Xiaofeng Wang, ${ }^{\mathrm{b}}$ Zhaogang Teng (D) ${ }^{\mathrm{c}}$ and Xiaoyang Liu (D) *b
}

\begin{abstract}
A series of nanoscale amorphous calcium carbonate (nano-ACC) precipitates are prepared by alternating the concentration of carboxylic acid-terminated $\mathrm{G} 0.5$ poly(amidoamine) dendrimer with a $\mathrm{CaCl}_{2}-$ $\mathrm{Na}_{2} \mathrm{CO}_{3}$ liquid-liquid phase which acts as a nucleation site at a fixed initial $\mathrm{pH}$ of $12 \pm 0.2$ at $15{ }^{\circ} \mathrm{C}$. Analysis of the reaction time and particle size shows a four stage ACC precipitation mechanism including a combination of primary nucleation, secondary nucleation and diffusion controlled fast and slow growth, which is proved by electrical conductivity (EC) experiments. Moreover, the crystallization of calcite via vaterite is investigated. It is found that the stabilization of ACC and delay of the transformation from ACC to calcite via vaterite in aqueous systems is due to the surface activity and dendritic effect of G0.5, which have a significant effect on the kinetic process of the ACC nucleation stage.
\end{abstract}

\section{Introduction}

The topic of crystallization or precipitation has been extensively studied for more than a century ${ }^{1,2}$ owing to its inherent significance in natural and technological applications, including environmental processes such as the carbon cycle and synthesis of nanomaterials, biomaterials and catalysts. ${ }^{3,4}$ It is widely recognized that most observed crystallizations go through an amorphous precursor phase, particularly in carbonates.

Amorphous calcium carbonate (ACC) is an important precursor in biominerals and crystalline $\mathrm{CaCO}_{3}$ minerals (calcite, vaterite and aragonite) and has attracted great interest in research. ACC is unstable and easily crystallized within minutes in water particularly under alkaline conditions. ${ }^{5-9} \mathrm{~A}$ strategy frequently employed is the use of specialized organic or inorganic additives, including $\mathrm{SiO}_{2}$, metal cations, poly(acrylic acid and aspartic acid) and block copolymers ${ }^{10-13}$ to stabilize the amorphous phase, where they provide a means of gaining desired properties, such as polymorphism and specific size distribution. Recently, stable amorphous calcium carbonate composite particles with sizes controlled in the range of 0.61 to $2.21 \mu \mathrm{m}$ were obtained using G0.5 poly(amidoamine) (PAMAM)

${ }^{a}$ Provincial Key Laboratory of Oil \& Gas Chemical Technology, College of Chemistry \& Chemical Engineering, Northeast Petroleum University, Daqing 163318, China. E-mail:wangjun1965@yeah.net

${ }^{b}$ State Key Laboratory of Inorganic Synthesis and Preparative Chemistry, College of Chemistry, Jilin University, Changchun 130023, China. E-mail: liuxy@jlu.edu.cn 'Department of Medical Imaging, Nanjing Hospital, Nanjing 210002, China $\dagger$ Electronic supplementary information (ESI) available: Additional characterizations of the $\mathrm{CaCO}_{3}$ precipitates are provided. See DOI: $10.1039 / \mathrm{c} 7 \mathrm{ra0} 7169 \mathrm{~h}$ dendrimers. $^{14}$ Dendrimers are monodispersed macromolecules with a regular and highly branched threedimensional structure, which should be a good candidate to prolong the incubation time of amorphous calcium carbonate to 1 day due to the dendritic effect. However, few studies, particularly in strongly basic aqueous systems, have reported the kinetics and nanoscale mechanisms for the improvement in the stabilization of ACC.

The latest research on ACC precipitation describes a complex process of primary/secondary nucleation and diffusion controlled growth, which was established based on a thermodynamic-kinetic method in an aqueous system of $\mathrm{CaCl}_{2}-$ $\mathrm{Na}_{2} \mathrm{CO}_{3} / \mathrm{NaHCO}_{3}{ }^{15}$ Valuable insight into the entire precipitation process was gained with an average surface energy value in nucleation time for a defined particle size. In addition, an accurate and key point is that numerous surfaces are generated with ions, molecules, or clusters to further accelerate ideal secondary nucleation and/or aggregation and growth such as self-organized behavior in addition to the primary behavior. According to this thermodynamic-kinetic model, it is uncertain whether a dendrimer molecule could promote or delay nucleation and control the particle size and the kinetics of precipitation of calcium carbonate.

In this study, a series of nano-ACCs were fabricated in a $\mathrm{CaCl}_{2}-\mathrm{Na}_{2} \mathrm{CO}_{3}$ liquid-liquid phase which acted as a nucleation site in the presence of carboxylic acid-terminated G0.5 poly(amidoamine) dendrimer (hereafter G0.5). Further, we explore whether G0.5 could extend the lifetime of ACC in crystallization favored alkaline conditions. In addition, tremendous efforts have been made to stabilize the amorphous phase in solution by varying temperature and the G0.5 concentration. 
The plausible kinetic process was studied by measuring the surface tension of the entire system, which could be described indirectly by the Gibbs free energy barrier and nucleation rate according to the classical theory introduced by Nielsen ${ }^{\mathbf{1 6}}$ and Testino. ${ }^{17}$ Due to the rigorous approach employed, the mechanisms of dendrimer improvement in the ACC stabilization and its crystallization to calcite via vaterite are clarified using an in situ data collecting system for $\mathrm{pH}$ and electrical conductivity (EC).

As discussed in this research, the carboxylic-terminated G0.5 prevents the transformation of ACC to calcite (via vaterite) in aqueous systems owing to its surface activity and dendritic effect, which have a significant effect on the kinetic process of the nucleation stage.

\section{Results and discussion}

Nano-ACC precipitations were carried out with and without G0.5 under different experimental conditions. Although it is known that dendrimers could effectively control the crystal size of calcite and vaterite, ${ }^{14}$ the influence of G0.5 in improving the stabilization of ACC in aqueous systems is rarely documented.

Ninety associated plausible precipitation experiments were conducted in a relatively wide range of reaction times, temperatures and G0.5 concentrations, which is provided in the schematic diagram of the sample generation as shown in Fig. 1. In addition, $\mathrm{pH}$, which is one of most important physicochemical parameters, was fixed at 12 initially since it is theoretically proven that the ACC solubility decreases at higher $\mathrm{pH}$. In addition, a higher concentration of G0.5 could dissolve better at higher $\mathrm{pH}$. If the initial $\mathrm{pH}$ is greater than 12 , a large number of carboxylic acid groups of G0.5 should react with $\mathrm{NaOH}$, which could affect the $\mathrm{Ca}^{2+}$ complexation. A similar tendency was reported, where higher temperature will lower the ACC solubility and $\mathrm{CaCO}_{3}$ crystallizes easily, which might be due to the positive change in entropy. ${ }^{15}$

Therefore, experiments were conducted at the initial $\mathrm{pH}$ of 12 at $15{ }^{\circ} \mathrm{C}$, which guaranteed that precipitation occurred easily under controlled critical conditions. Due to the quantity of precipitate prepared, it was possible to completely characterize the samples via powder X-ray diffraction (pXRD), FT-IR spectroscopy, scanning electron microscopy (SEM) with energy dispersive X-ray spectroscopy (EDX) and thermogravimetric analysis (TGA). As the reaction progressed with temperature, the

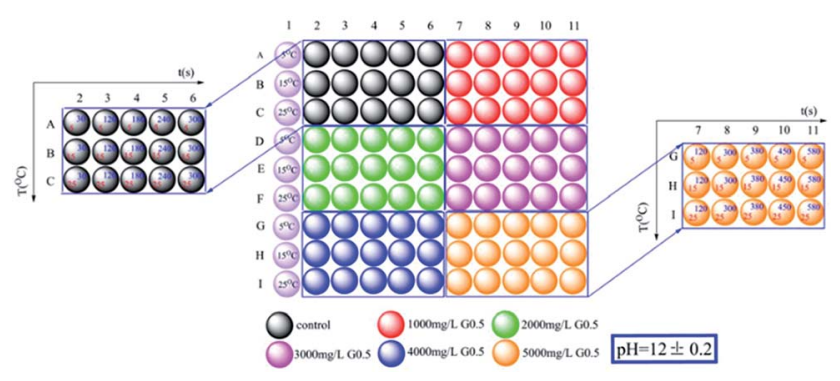

Fig. 1 Experimental sample precipitation design.
pXRD patterns of the ACC particles (Fig. S1 $\dagger$ ) prepared at $5{ }^{\circ} \mathrm{C}$ and $15{ }^{\circ} \mathrm{C}$ showed no Bragg peaks; however, broad humps located at $2 \theta=\sim 30^{\circ}$ and $\sim 45^{\circ}$ were observed, which reflect poorly ordered ACC particles. The broad humps narrowed with an increase in reaction time and vaterite (110), (112) and (114) peaks (intense peaks at $2 \theta=24.90^{\circ}, 27.05^{\circ}$ and $32.78^{\circ}$, respectively) started growing after an induction time of $120 \mathrm{~s}$, and $240 \mathrm{~s}$ later, calcite peaks (intense sharp peaks at $2 \theta=29.40^{\circ}$ and $35.97^{\circ}$; (104) and (110), respectively) appeared (Fig. S2a, $\dagger$ and 2). The G0.5-introduced ACC samples exhibited a similar amorphous and crystalline process, but there was a significantly different incubation time. As a result, the G0.5 postponed the crystallization from ACC to calcite (via vaterite), which particularly extended the maximum lifetime of ACC from $120 \mathrm{~s}$ (without G0.5) to $300 \mathrm{~s}$ (with G0.5), vaterite from $180 \mathrm{~s}$ to $380 \mathrm{~s}$, and pure calcite from $300 \mathrm{~s}$ to $580 \mathrm{~s}$ (Fig. S3a, $\dagger$ and 2), and controlled the particle size of ACC in the range of about 40-200 $\mathrm{nm}$ (Fig. 2 and 4).

The FT-IR analysis of the as-prepared samples showed bands characteristic of ACC (Fig. S2b and $\mathrm{S} 3 \mathrm{~b} \dagger$ ) with peaks corresponding to the main asymmetric $\nu_{3} \mathrm{CO}_{3}{ }^{2-}$ band (at $1472 \mathrm{~cm}^{-1}$ and $1423 \mathrm{~cm}^{-1}$ ) and a shaper band at $1650 \mathrm{~cm}^{-1}(\mathrm{O}-\mathrm{H}$ bending $)$, symmetric $\nu_{1} \mathrm{CO}_{3}{ }^{2-}$ peak at $1072 \mathrm{~cm}^{-1}$, the asymmetric $\nu_{2}$ peak at $866 \mathrm{~cm}^{-1}$ and no detectable symmetric $\nu_{4}$ peak $\left(745 \mathrm{~cm}^{-1}\right.$ in vaterite or $713 \mathrm{~cm}^{-1}$ in calcite). After $120 \mathrm{~s}$ reaction in a pure aqueous system or after $300 \mathrm{~s}$ reaction in a $5000 \mathrm{mg} \mathrm{\textrm {L } ^ { - 1 }}$ G0.5-water system, vaterite-like features appeared with all the expected IR active modes visible and sharpening of the peaks at $875 \mathrm{~cm}^{-1}$ and $745 \mathrm{~cm}^{-1}$. This confirmed that the ACC crystallized into vaterite, and small peaks of calcite were observed in the patterns collected from the samples recovered after $240 \mathrm{~s}$ and $450 \mathrm{~s}$ (without and with G0.5 successively), which appeared at $875 \mathrm{~cm}^{-1}$ and $713 \mathrm{~cm}^{-1} \cdot{ }^{18,19}$

The morphologies of all the obtained $\mathrm{CaCO}_{3}$ were determined via SEM. It should be emphasized that the exhaustive experiments were designed to prepare different types of products in order for us to examine the strong influence of G0.5 on the $\mathrm{CaCO}_{3}$ morphologies and the precipitation process through particle size, configuration and stabilization. Specifically, spherical ACC particles with a diameter of $\sim 220 \mathrm{~nm}$ were
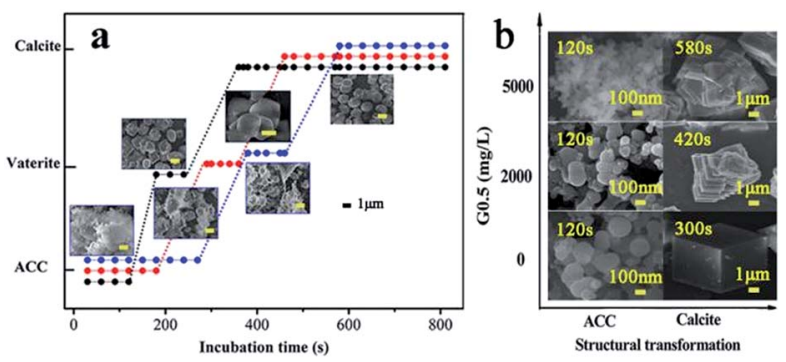

Fig. 2 (a) Schematic diagram of the $\mathrm{CaCO}_{3}$ structural transformation from ACC to calcite via vaterite with different concentrations of G0.5

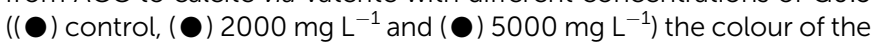
spherules should be black (control), red (2000 $\left.\mathrm{mg} \mathrm{L}^{-1}\right)$ and blue $(5000$ $\mathrm{mg} \mathrm{L}^{-1}$ ), respectively versus incubation time, which was obtained with a combination analysis of the pXRD, FTIR and SEM results and (b) schematic diagram of the $\mathrm{CaCO}_{3}$ structural transformation by SEM. 
observed in the samples prepared with the pure water system after $120 \mathrm{~s}$ (Fig. 4($\left.\left(\mathrm{d}_{1}\right)\right)$. The crystallization phase could be identified clearly as $1-2 \mu \mathrm{m}$ vaterite and $2-3 \mu \mathrm{m}$ calcite particles (Fig. 2), effectively concluding that this amorphous phase is often short-lived, and crystallized within 3 minutes. ${ }^{20}$ However, there was a progressive downward shift in the particle size of ACC, vaterite and calcite and an upward shift in the lifetime of each type of $\mathrm{CaCO}_{3}$ when the ACC was prepared in the G0.5 (Fig. 2). The maximum shifts in the extended incubation time and particle size were $300 \mathrm{~s}$ and $200 \mathrm{~nm}$ for ACC (Fig. $4\left(\mathrm{~d}_{2}\right)$ ), $450 \mathrm{~s}$ and $\sim 1.5 \mu \mathrm{m}$ for vaterite and $580 \mathrm{~s}$ and $\sim 2.5 \mu \mathrm{m}$ for calcite with $5000 \mathrm{mg} \mathrm{L}^{-1} \mathrm{G} 0.5$, respectively. These results are fully consistent with the fact that carboxylic acid functionalized groups are effective $\mathrm{CaCO}_{3}$ growth modifiers, ${ }^{21}$ which are attributed to the dispersion of the dendritic effect and the coordination binding to $\mathrm{Ca}^{2+}$. Further, it verifies that G0.5 is a stabilizer for ACC and crystal inhibitor for calcite and vaterite.

Thermogravimetric analysis was performed to gain information on the existence of G0.5 in the composition of the ACC, which underwent two-step (without G0.5) and three-step (with G0.5) weight loss upon heating (Fig. 3a). The weight loss started with a gradual loss in structural and surface water, which was $4.9 \mathrm{wt} \%$ for $5000 \mathrm{mg} \mathrm{L}^{-1} \mathrm{G} 0.5$ in the early period before $270{ }^{\circ} \mathrm{C}$. Recently, the studies on ACC structures ${ }^{22,23}$ have provided surprisingly conclusive insights towards controlling its synthesis and typical polyamorphous states. Water in the hydrated form plays an important role in ACC polyamorphism since it is composed of structural and surface-bound $\mathrm{H}_{2} \mathrm{O}^{24}$ As a result, ACC was in the form of $\mathrm{CaCO}_{3} \cdot 1.10 \mathrm{H}_{2} \mathrm{O}$ without $\mathrm{G} 0.5$ and $\mathrm{CaCO}_{3} \cdot 1.23 \mathrm{H}_{2} \mathrm{O}$ with $5000 \mathrm{mg} \mathrm{L}^{-1} \mathrm{G} 0.5$, which is visualized in Fig. S4. $\dagger$

Specifically, the $\mathrm{pH}$ of the preparation solution is important for defining not only the synthetic conditions, but also $\mathrm{OH}^{-}$ containing species that could be incorporated into the amorphous structure. When pure ACC was obtained at an initial $\mathrm{pH}>$ 12 , additional weight loss would take place at $270-650^{\circ} \mathrm{C}$ owing to the formation or decomposition of $\mathrm{Ca}(\mathrm{OH})_{2},{ }^{25}$ which is consistent with this study as shown in curve I (Fig. 3a). Importantly, it is demonstrated that the ACC particles underwent a slow dehydration, beyond which the classical sequential decomposition of $\mathrm{CaCO}_{3}$ to $\mathrm{CaO}$ was observed (weight loss of 33-38 wt\% up to $810{ }^{\circ} \mathrm{C}$ ). The additional weight loss step in curve II at $400-650^{\circ} \mathrm{C}$ belongs to the carbonization temperature of G0.5 (Fig. 3a). This suggests that the G0.5 molecules are adsorbed on (or reside in) ACC with a content of $6.26 \mathrm{wt} \%$. The

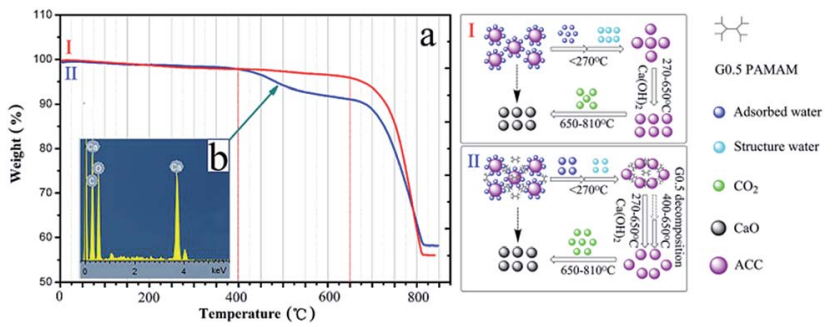

Fig. 3 Chemical composition of ACC analysed by (a) TGA: (I) control and (II) $5000 \mathrm{mg} \mathrm{L}^{-1} \mathrm{G} 0.5$ and (b) EDX of ACC with $5000 \mathrm{mg} \mathrm{L}^{-1} \mathrm{G} 0.5$. rate of $\mathrm{CO}_{2}$ loss during the second major period differed, and a slower weight loss was observed in the system with G0.5. This result indicates that the ACC particles modified with G0.5 exhibit a strong stabilizing effect that prevents phase transformation, which means that a G0.5- $-\mathrm{Ca}^{2+}$ complex could exist as identified by the EDX analysis (Fig. 3b). The EDX result indicates the presence of calcium $(3.7,4.0 \mathrm{keV})$, carbon $(0.3 \mathrm{keV})$ and oxide $(0.5 \mathrm{keV})$ in the form of aggregates (Fig. $3 \mathrm{~b})$. This gave us a clear insight into the distribution of elements and that the carbon atom spectrum was larger than that in the standard $\mathrm{CaCO}_{3}$, which indicates that the separations between the monofilaments correspond to the adsorbed layers of G0.5 that prevented the transformation of ACC, and contaminated dendrimers were involved in the products.

\section{Nanoscale precipitation mechanism of ACC with G0.5}

Despite the fact that there were hundreds of scientific contributions published over the last 10 years on the precipitation of ACC, both its mechanism and kinetic aspects are still unclear. Therefore, detailed time distribution experiments for $5000 \mathrm{mg}$ $\mathrm{L}^{-1} \mathrm{G} 0.5$ and control experiments were designed based on the nano-ACC precipitation pathway to solve these unanswered questions.

Our experimental data on reaction time and particle size exhibits a four stage trend during the ACC precipitation (Fig. 4), which is a combination of primary nucleation (stage I), secondary nucleation (stage II) and diffusion controlled growth (fast: stage III and slow: stage IV). The growth could be limited by the diffusion of $\mathrm{Ca}^{2+}, \mathrm{CO}_{3}{ }^{2-}$, their interaction with the G0.5 additive and the ACC surface energy, which is consistent with the classical nucleation theory described by Nielsen. ${ }^{1}$

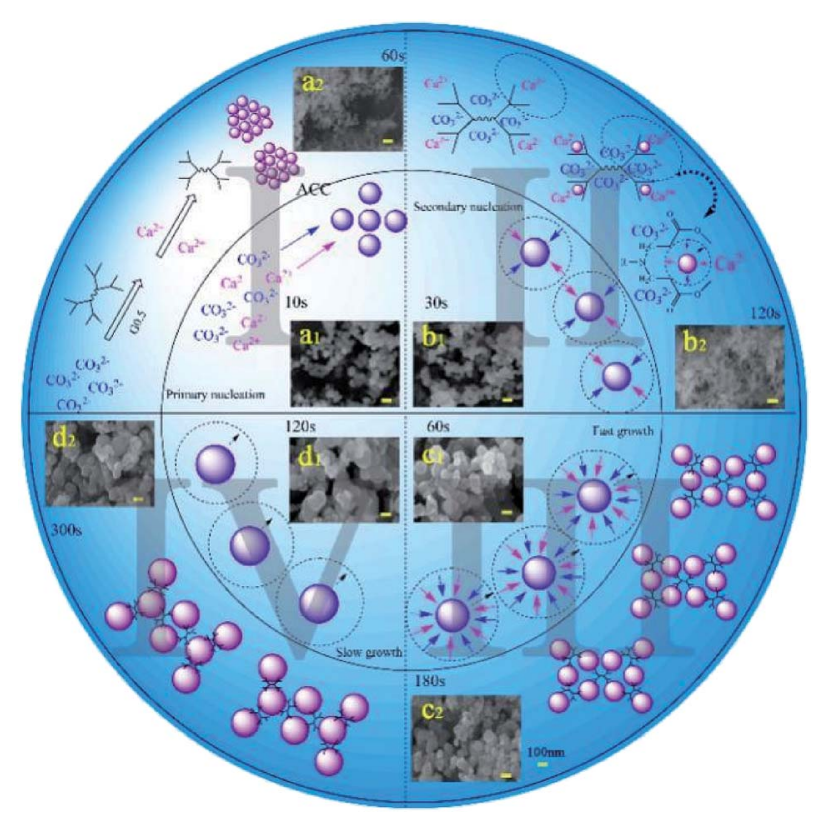

Fig. 4 Schematic depiction of the formation of amorphous calcium carbonate spherulites in two different conditions: inner circle (control) and outer circle (G0.5). 
Initially, some clusters composed of $\mathrm{Ca}^{2+}$ and $\mathrm{CO}_{3}{ }^{2-}$ ions triggered quick primary nucleation, which was named stage I. Then, the secondary particles were properly regarded as "aggregates" obtained by secondary nucleation, which was called stage II. The particles in these two stages were quite different in quantity but similar in particle size, which is $\sim 50 \mathrm{~nm}$ (Fig. $4 \mathrm{a}_{1}$ and $\mathrm{b}_{1}$ ). In the pure water system, the precipitation pathway had no restriction, but what must be emphasized is that G0.5 on the surface of the obtained particles could inhibit aggregation as well as the particle-particle preferential orientation. ${ }^{26}$ The distribution of G0.5 and $\mathrm{CO}_{3}{ }^{2-}$ ions was disordered due to the electrostatic repulsion in the early stage, which is plausibly supported by simply considering the fact that $\mathrm{CO}_{3}{ }^{2-}$ was rich during the primary nucleation and secondary nucleation stages. ${ }^{27}$ Thus, they should have a relatively high negative charge, which could prevent their coalescence and lead to a smaller size $(\sim 40 \mathrm{~nm})$ and prolonged time $(\sim 120 \mathrm{~s})$ in the nucleation stages (Fig. $4 \mathrm{a}_{2}$ and $\left.\mathrm{b}_{2}\right) .^{28}$

Finally, the small particles grew rapidly, which was due to the fast consumption of $\mathrm{Ca}^{2+}$ in stage III until an almost steady-state value in stage IV, where the particles grew at a slower rate as no consumable ions were available at end of the rapid process. As a result, with the addition of $\mathrm{Ca}^{2+}$ ions, the $\mathrm{G} 0.5-\mathrm{Ca}^{2+}$ complex rapidly formed, which turned into the intermediates that slowly converted into ACC particles. Evidence in Fig. $4\left(c_{1}, c_{2}, d_{1}\right.$ and $\left.d_{2}\right)$ shows a comparably smaller growth in size of the particles $(150 \mathrm{~nm})$ and a longer incubation of $180 \mathrm{~s}$ in stage III. During stage IV, pure ACC ( $200 \mathrm{~nm})$ was stabilized in $300 \mathrm{~s}$ with G0.5, but only in $120 \mathrm{~s}$ without G0.5. This is mainly because the stable G0.5- $\mathrm{Ca}^{2+}$ complex might inhibit the formation of calcium carbonate particles, resulting in no $\mathrm{Ca}^{2+}$ ions dissociated with $\mathrm{CO}_{3}{ }^{2-}$ during the precipitation process. This mechanism is supported by the EDX results (Fig. 3b), which clearly show that G0.5 adsorbed on the original ACC might inhibit the growth of initially formed ACC particles due to the steric-hindrance effect and is consistent with the study reported by Kensuke Naka. ${ }^{\mathbf{1 4}}$

Another effective means of investigating the degree of disorder generated in the ACC samples is Raman spectroscopy, which could elaborate the inhibition of G0.5 (Fig. 5). The change in the positions and widths of the molecular vibrations due to the various atomic configurations and environments of the carbonate groups could provide information about the disorder in the structure. Raman spectra were obtained in the range of 1000$1200 \mathrm{~cm}^{-1}$ with a scan time of $120 \mathrm{~s}$, and spectra were obtained from five samples with different concentrations ranging from 1000-5000 $\mathrm{mg} \mathrm{L}^{-1}$ (Fig. 5a). The strongest $\nu_{1}$ peak at $\sim 1080 \mathrm{~cm}^{-1}$ (C-O symmetrical stretching) was selected for analysis, which was used as the metric for disorder. The $\mathrm{C}-\mathrm{O}$ symmetrical stretching peak showed a gradual blue shift (Fig. 5b), which indicates that steric-hindrance effect and electrostatic repulsion of G0.5 clearly restrict the space scale of the $\nu_{1}$ vibration leading to a higher rate of dipole change in the $\mathrm{C}-\mathrm{O}$ symmetrical stretching. Also, the trend of increasing FWHM demonstrates that a disordered structure formed in the carbonate lattice mode, which may be correlated with an increasing tendency in the direction of the growth edges and sites (Fig. 5b).

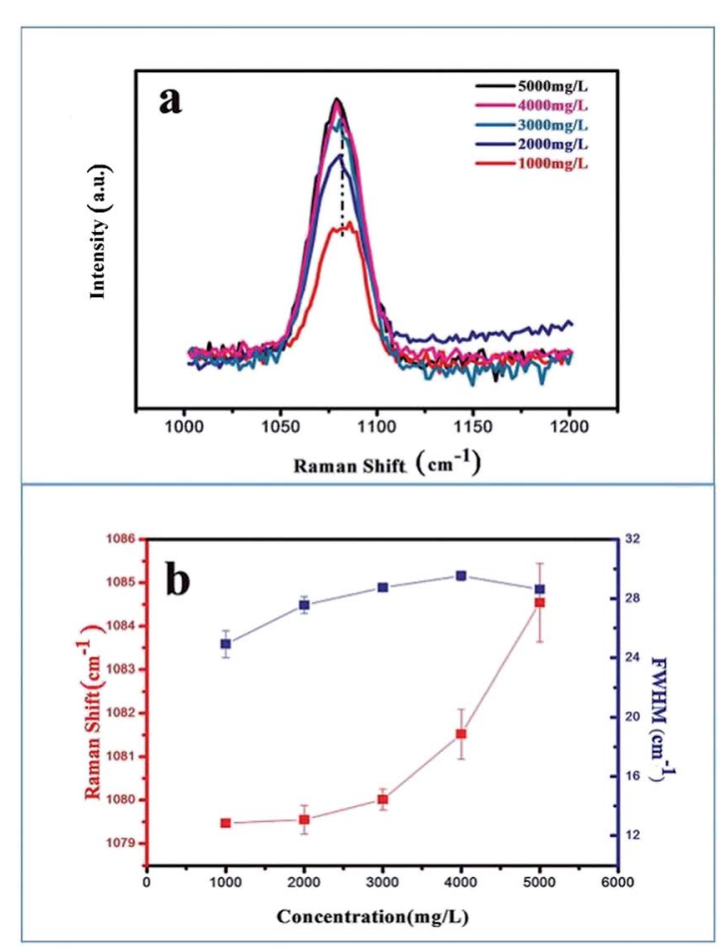

Fig. 5 Structure analysis by Raman microscopy. (a) Raman spectra taken from ACC particles at concentrations of G0.5 ranging from 1000 to $5000 \mathrm{mg} \mathrm{L}^{-1}$. (b) $\mathrm{C}-\mathrm{O}$ symmetrical stretch vs. its FWHM at approximately $1080 \mathrm{~cm}^{-1}$.

Besides, similar experiments were carried out during the crystallization of calcite via vaterite. G0.5 with carboxylic groups is a new class of anionic dendrimers which displays a variety of aggregation states owing to its conformational flexibility, and its surface was proposed as a nucleation site, whereas its surface branch cells compete with $\mathrm{CO}_{3}{ }^{2-} .^{29,33,34}$

From a nucleation and crystal growth point of view, the electrical conductivity and $\mathrm{pH}$ of the $\mathrm{CaCO}_{3}$ precipitation process was monitored as a function of incubation to capture detailed information on the $\mathrm{CaCO}_{3}$ transformation (Fig. 6). The electrical conductivity value decreased at a rapid rate due to the consumption of $\mathrm{Ca}^{2+}$ and $\mathrm{CO}_{3}{ }^{2-}$ in the initial $\mathrm{CaCO}_{3}$ precipitation process and reached a minimum on completion of the precipitation process. From the variation in the electrical conductivity, delayed nucleation was observed in the presence of $5000 \mathrm{mg} \mathrm{L}^{-1} \mathrm{G} 0.5$ as compared to the control. The transformation of $\mathrm{CaCO}_{3}$, which was formally split into four zones related to ACC, ACC + vaterite, vaterite + calcite and calcite, during the entire experiment could be derived. First is the ECdecreasing fast step within $300 \mathrm{~s}$ named zone $\mathrm{A}$, in which pure ACC was generated and stable. In zone A, a four stage mechanism of ACC precipitation was recorded with no significant difference in EC values. During the decreasing step, the EC stopped decreasing between 60-120 s, which was an amazing coincidence with the phenomena of primary nucleation (stage I) and secondary nucleation (stage II). In addition, the constant electrical conductivity at $180 \mathrm{~s}$ and $300 \mathrm{~s}$ is in accordance with fast growth (stage III) and slow growth (stage IV), respectively. However, $10 \mathrm{~nm}$ sized nanoparticles existed in both growth 


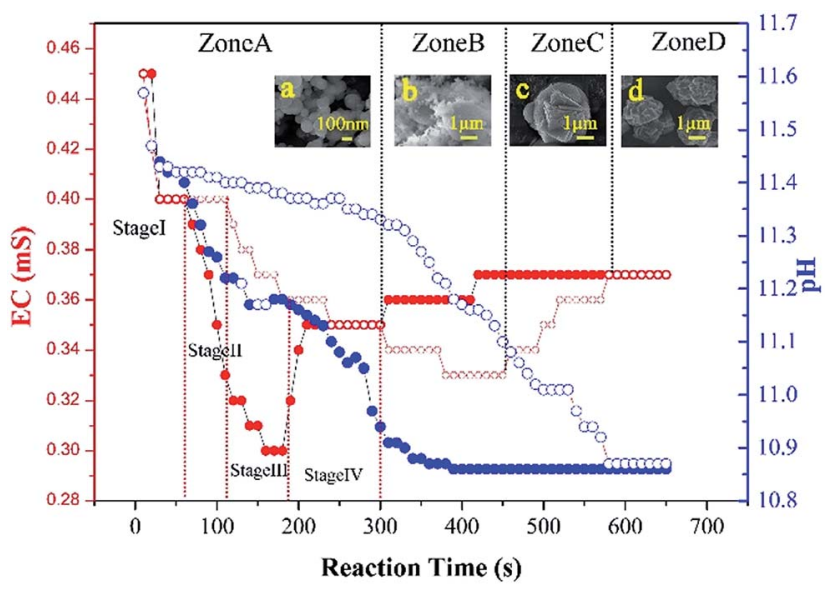

Fig. 6 Variation in the electrical conductivity (EC) and $\mathrm{pH}$ versus incubation time and visual evidence by SEM (insets $a-d)((\mathbf{O})$ : control EC, $(\mathbf{O})$ : control $\mathrm{pH}$, the colour of the spherules should be red (EC) and blue $(\mathrm{pH})$, respectively. $(\mathrm{O}): 5000 \mathrm{mg} \mathrm{L}^{-1} \mathrm{GO} .5 \mathrm{EC}$, and $(\mathrm{O})$ : $5000 \mathrm{mg} \mathrm{L}^{-1} \mathrm{G} 0.5 \mathrm{pH}$ ). The circles should be red colour (EC) and blue colour $(\mathrm{pH})$, respectively.

stages, where the Ostwald ripening process related to dissolution and reprecipitation occurred, which is attributed the success of the diffusion of G0.5.

Secondly, the electrical conductivity increased via a low ebb valley, where the transformation of ACC to vaterite was due to an internal structural reorganization within the individual nanoparticles, which occurred from $300 \mathrm{~s}$ to $450 \mathrm{~s}$ and was named zone B. Third, the electrical conductivity increased, leading to the transformation of vaterite to calcite from $450 \mathrm{~s}$ to $580 \mathrm{~s}$, which was named zone C. Our findings, which were proven by SEM images (insets of Fig. 6a-d), are in agreement with the recent literature, where $\mathrm{CaCO}_{3}$ particles dissolve and release calcium and carbonate into the solution and then reprecipitate on a solid surface and transform into vaterite or calcite. $^{30}$

Finally, pure calcite was generated with the electrical conductivity reaching a certain value, which was named zone D. Also, most of the calcites were polycrystalline particles due to the carboxylic acid functionalized groups of G0.5, which act as efficient crystal modifiers. ${ }^{31}$ The SEM images as additional proof show the same trend of extending the stable time for G0.5, where the $\mathrm{pH}$ value dropped rapidly due to the consumption of $\mathrm{CO}_{3}{ }^{2-}$ ions and remained unchanged in the $\mathrm{CaCO}_{3}$ precipitation process, and the prolongation of the $\mathrm{pH}$ stable period with G0.5 is attributed to the corresponding solution behavior.

\section{Kinetic stabilization of nanoscale ACC with G0.5}

According to crystalline materials theory ${ }^{16}$ and computation of ACC through the discretized population balance approach, ${ }^{17}$ the kinetics of the nanoscale precipitation of ACC was investigated to determine the influence of the additive G0.5 on dramatically extending the ACC lifetime, where changes in the solution properties due to surface tension were recorded in the precipitation solution.
Here, eqn (1) is provided as a combination of nucleation and growth of the $\mathrm{CaCO}_{3}$ particle, which was fractionated, and the elementary processes were the primary nucleation, the secondary nucleation and the diffusion controlled growth.

$$
\frac{\mathrm{d} N_{i}}{\mathrm{~d} t}=\left(\frac{\mathrm{d} N_{i}}{\mathrm{~d} t}\right) \text { prim. nucl. }+\left(\frac{\mathrm{d} N_{i}}{\mathrm{~d} t}\right) \text { sec. nucl. }+\left(\frac{\mathrm{d} N_{i}}{\mathrm{~d} t}\right) \text { growth }
$$

If $N_{i}$ is the number of particles in the $i^{\text {th }}$ size class, the variation $\mathrm{d} N_{i} / \mathrm{d} t$ could be split into the different contributions related to the elementary processes. In particular, the growth algorithm was computed using 4 stages of ACC particle size distribution as a consequence of the simultaneous events of primary nucleation, secondary nucleation, fast growth and slow growth. Growth was assumed to occur by the incorporation of $\mathrm{Ca}^{2+}$ and $\mathrm{CO}_{3}{ }^{2-}$ ions into the solid phase particles, which is a function of the diffusion and activity coefficient of $\mathrm{Ca}^{2+}$ and $\mathrm{CO}_{3}{ }^{2-}$, and the solubility product $K_{\mathrm{sp}}$ was determined by temperature and $\mathrm{pH}$. Owing to the fixed experimental conditions of temperature $15{ }^{\circ} \mathrm{C}$ and initial $\mathrm{pH} 12$, the diffusion controlled growth stages could be ignored. However, the SEM images indicate that the ACC particles indeed grew slower with time and smaller in size; thus, the diffusion of $\mathrm{Ca}^{2+}$ and $\mathrm{CO}_{3}{ }^{2-}$ could be influenced by the unbalanced viscosity and solution properties with G0.5. Therefore, the nucleation stages (B1 primary nucleation rate, eqn (2); B2 secondary nucleation rate, eqn (3); and Gibbs free energy barrier for nucleation, eqn (4)) are crucial to the kinetics to study the precipitation of ACC.

$$
\begin{gathered}
B_{1}=\frac{2 D}{d^{5}} \exp \left(-\frac{\Delta G_{1}^{*}}{k_{\mathrm{B}} T}\right) \\
B_{2}=\frac{2 D}{d^{4}} \exp \left(-\frac{\Delta G_{2}^{*}}{k_{\mathrm{B}} T}\right) A_{\mathrm{T}} \\
\Delta G_{n}^{*}=\frac{4}{27} \frac{\varepsilon_{\mathrm{A}}^{3}}{\varepsilon_{\mathrm{V}}^{2}} \frac{v^{2} \gamma^{3}}{k_{\mathrm{B}}^{2} T^{2} \ln ^{2}(S)}
\end{gathered}
$$

where, $B_{n}$ is the nucleation rate, $D$ is the diffusion coefficient of the solute, $d$ could be approximated with the molecular diameter of the solute, $\Delta G_{n}^{*}$ is the Gibbs free energy barrier for nucleation ( $n=1$ or 2$), A_{\mathrm{T}}$ is the coefficient for secondary nucleation (here the overall particle surface is a positive number), $\varepsilon_{\mathrm{A}}$ is the surface geometrical factor, $\varepsilon_{\mathrm{V}}$ is the volumetric geometrical factor and $v$ is the molecular volume.

Combining eqn (2) and (3) with (4), it is worth noting that only the surface tension, $\gamma$, is a key parameter to study how G0.5 acted to delay the precipitation of ACC through kinetics. The surface tension of the ACC solution $(\gamma)$ against G0.5 concentration and time is plotted in Fig. 7, which defines the nucleation rate. At $15^{\circ} \mathrm{C}$ and initial $\mathrm{pH}$ of 12 , the value of $\gamma$ decreased from $55 \mathrm{mN} \mathrm{m}^{-1}$ to $45 \mathrm{mN} \mathrm{m}^{-1}$, which was affected by the G0.5 concentration. In contrast, the $\gamma$ of the pure water system was $72.5 \mathrm{mN} \mathrm{m}^{-1}$ (Fig. 7a). In the $5000 \mathrm{mg} \mathrm{L}^{-1}$ G0.5 solution, the surface tension significantly decreased to $38 \mathrm{mN} \mathrm{m}^{-1}$ at the beginning of precipitation within $120 \mathrm{~s}$ and there was no change 


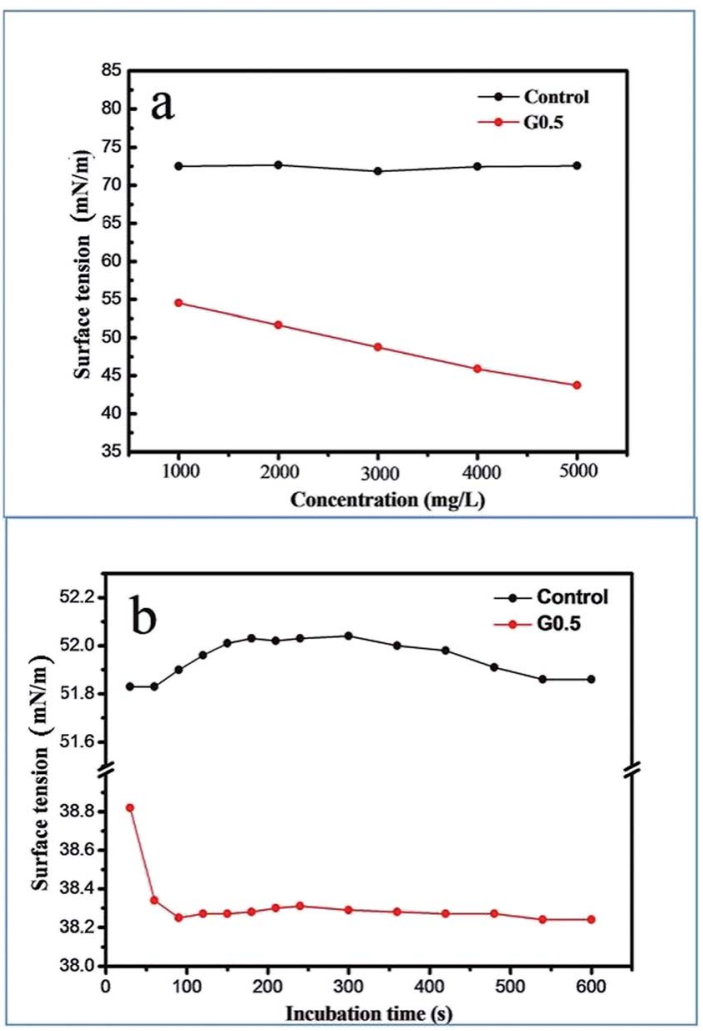

Fig. 7 Surface tension of the reaction solutions with $5000 \mathrm{mg} \mathrm{L}^{-1}$ G0.5 and the control.

during the other time periods, which supports the fact that the ACC nucleation was influenced by the surface tension of the G0.5 solution (Fig. 7b). Moreover, the contact angle was determined to be $27.11^{\circ}$ (Fig. S6 $\dagger$ ), which clarifies that the surface energy of ACC was lower due to the adsorption of G0.5. Ultimately, the kinetic inhibition of nucleation was a result of the energy barrier together with the lower nucleation rate, which led to a longer lifetime for ACC.

\section{Experimental}

\section{Materials}

Calcium chloride $\left(\mathrm{CaCl}_{2}\right)$, sodium carbonate $\left(\mathrm{Na}_{2} \mathrm{CO}_{3}\right)$, sodium hydroxide $(\mathrm{NaOH})$ and ethyl alcohol $\left(\mathrm{CH}_{3} \mathrm{CH}_{2} \mathrm{OH}\right)$ were purchased from the Tianjin Chemical Reagent Factory. All chemicals were of analytical grade and used without further purification. Deionized water was used to prepare aqueous solutions of $\mathrm{CaCl}_{2}$ and $\mathrm{Na}_{2} \mathrm{CO}_{3}$ just before the precipitation experiment, which were prepared in our laboratory. In all the reaction systems, PAMAM solutions were only added to the $\mathrm{Na}_{2} \mathrm{CO}_{3}$ solution before mixing with the $\mathrm{CaCl}_{2}$ solution. Carboxylic-terminated G0.5 PAMAM dendrimers (hereinafter G0.5) were synthesized in our laboratory; the detailed procedure is reported in our previous study. ${ }^{32}$ As shown in Fig. S6, $\dagger$ the structures were dendritic shapes in the early stages of generation, whereas the surface branch cells became substantially more rigid later on. ${ }^{33}$ The anionic dendrimers should be a good candidate for studying the precipitation of $\mathrm{CaCO}_{3}$ due to their unique and well-defined structures. Also, under a certain concentration, G0.5 with carboxylic groups at the external surface was proposed as a mimic of anionic micelles, which could improve the properties of the solution. ${ }^{34}$

\section{Formation of amorphous calcium carbonate nanoparticles}

Aqueous solutions of $\mathrm{CaCl}_{2}\left(0.5 \mathrm{~mol} \mathrm{~L}{ }^{-1}, 100 \mathrm{~mL}\right), \mathrm{Na}_{2} \mathrm{CO}_{3}$ $\left(0.5 \mathrm{~mol} \mathrm{~L}^{-1}, 100 \mathrm{~mL}\right), \mathrm{NaOH}\left(0.2 \mathrm{mg} \mathrm{L}{ }^{-1}, 50 \mathrm{~mL}\right)$ and a certain concentration of G0.5, ranging from 1000 to $5000 \mathrm{mg} \mathrm{L}^{-1}$, (prepared system) were initially prepared. ACC was synthesized according to Kojima's method, ${ }^{35}$ where equimolar calcium chloride and sodium carbonate solutions were rapidly mixed. In this method, a small amount of $\mathrm{NaOH}$ solution was added to $10 \mathrm{~mL} 0.5 \mathrm{M} \mathrm{Na}_{2} \mathrm{CO}_{3}$, different concentrations of G0.5 solution and a quantitative amount of deionized water; the $\mathrm{pH}$ value was adjusted to 12.00 using a dilute aqueous solution of $\mathrm{NaOH}$. This solution was combined with $10 \mathrm{~mL} 0.5 \mathrm{M} \mathrm{CaCl}_{2}$ solution at temperatures ranging from $5{ }^{\circ} \mathrm{C}$ to $25{ }^{\circ} \mathrm{C}$ and stirred rapidly, followed by vacuum filtration with ethanol. Subsequently, the powder was filtered and washed with $\mathrm{CH}_{3} \mathrm{CH}_{2} \mathrm{OH}$ once. The designed precipitation of $\mathrm{CaCO}_{3}$ in the absence/presence of G0.5 was performed under different nucleation conditions (Fig. 1). Finally, the product was dried in an oven at $45{ }^{\circ} \mathrm{C}$ for $24 \mathrm{~h}$ and used for further measurements, through which we found that amorphous calcium carbonate was better stabilized in the surrounding conditions at $15{ }^{\circ} \mathrm{C}$ with $5000 \mathrm{mg} \mathrm{L}^{-1} \mathrm{G} 0.5$ additive.

\section{Characterization}

The morphology of the ACC samples was determined using a scanning electron microscope (SEM) on a Zeiss $\sum$ IGMA at an accelerating voltage of $10 \mathrm{kV}$. Samples were fixed with adhesive conducting pads. Structural qualitative identification of $\mathrm{CaCO}_{3}$ was conducted via Raman microscopy using a Renishaw ViaRaman microscope equipped with a solid state $250 \mathrm{~mW}$ laser at $785 \mathrm{~nm}$, and FTIR spectral measurements were performed on a Tensor 27 using $\mathrm{KBr}$ pellets at a scanning rate of 5 times per minute. The PEAKFIT V4.12 software was used to refine the Raman shifts. All off-line solids were characterized via powder $\mathrm{X}$-ray diffraction (pXRD) on a Rigaku D/max 2200pc diffractometer fitted with a $\mathrm{Cu}-\mathrm{K} \alpha(1.54 \AA)$ radiation source under the setting conditions of $40 \mathrm{kV}, 20 \mathrm{~mA}$. Approximately 5-8 mg samples were weighed into a platinum crucible. Simultaneous TG measurements were performed using a ULVAC TGD-9600 at a heating rate of $15 \mathrm{~K} \mathrm{~min}^{-1}$ under flowing $\mathrm{N}_{2}\left(60 \mathrm{~cm}^{3} \mathrm{~min}^{-1}\right)$. Elemental analysis was carried out using an energy dispersive X-ray analyzer (EDX), which was directly connected with the SEM at an accelerating voltage of $20 \mathrm{kV}$. The $\mathrm{pH}$ and electrical conductivity data were recorded on-line using a PHS-3C Precision $\mathrm{pH} / \mathrm{mV}$ meter and DDS-11A electrical conductivity meter, respectively. The surface tension of the entire solution was measured on a QBZY-2 surface tension meter using the Wilhelmy platinum plate method and the contact angle of ACC was determined using a DS-360A contact angle meter, which could 
accurately describe the surface energy of particles and the variation in the nucleation stage.

\section{Conclusions}

This study presented the role of G0.5 PAMAM dendrimers in the precipitation of calcium carbonate. Although this was already proven by preliminary experiments, our experimental results provide more powerful evidence and the mechanism that multiple functions of G0.5 stabilize nano-ACC and prevent the transformation of ACC to calcite (via vaterite) in strongly basic aqueous systems. The precipitation process of nano-ACC is divided into primary/secondary nucleation stages and fast/slow growth stages, which are analogous to a thermodynamickinetic model except for the lifetime and particle size. ${ }^{15}$ The electrostatic repulsion between $\mathrm{G} 0.5$ and $\mathrm{CO}_{3}{ }^{2-}$ ions results in a disordered distribution leading to a $\mathrm{CO}_{3}{ }^{2-}$ rich phase during the primary nucleation and secondary nucleation stages ${ }^{21}$ and the $\mathrm{G} 0.5-\mathrm{Ca}^{2+}$ complex restrictively releases $\mathrm{Ca}^{2+}$. This caused the fast/slow growth stages to proceed slowly, where the $\mathrm{C}-\mathrm{O}$ symmetrical stretching vibration in the carbonate lattice mode is confined in the direction of the growth edges or sites. The surface tension of the precipitation solution is related to kinetics factors and indirectly reflects the Gibbs free energy barrier, which could lower the nucleation rate. ${ }^{16,17}$ In addition, the on-line data collection method involving $\mathrm{pH}$ and electrical conductivity is an effective strategy to explore the precipitation mechanism and process of ACC, which could detect the stability of the metastable phase originating from the slower transport of ions and nucleation rate of the precursor particles. This method provided a route to obtain desired properties such as polymorphism, specific size distribution, extra long stable lifetime and even steady synthetic process. These results suggest that almost all processes of the fast reaction and fast crystallization $v i a$ an amorphous phase or unstable metastable phase would be difficult to identify. Moreover, the relationship between the different generations of dendrimer, structural $\mathrm{H}_{2} \mathrm{O}$, stabilization and polymorph of ACC is still poorly understood. Further studies are required to characterize the transformation process using in situ methods, synchrotron radiation techniques or three-dimensional imaging methods to fully understand the formation mechanisms and kinetics of this material.

\section{Conflicts of interest}

There are no conflicts to declare.

\section{Acknowledgements}

This study was financial supported by National Natural Science Foundation of China (grant No. 51404069), the State Key Laboratory Opening Project Foundation of Jilin University, Research Project of Northeast Petroleum University and Graduate Student Innovation Research Project of Northeast Petroleum University (grant No. YJSCX2017-017NEPU). We are grateful to Zhaohui Dong of Shanghai Synchrotron Radiation
Facility (SSRF) for characterization suggestions and microscopic test center of the Northeast Petroleum University.

\section{Notes and references}

1 C. V. Burton, Philos. Mag., 1892, 33, 191-204.

2 J. J. De Yoreo and P. G. Vekilov, Rev. Mineral. Geochem., 2003, 54, 57-93.

3 A. Myerson, Handbook of industrial crystallization, Butterworth-Heinemann, 2002.

4 J. Rieger, M. Kellermeier and L. Nicoleau, Angew. Chem., Int. Ed., 2014, 53, 12380-12396.

5 L. Addadi, S. Raz and S. Weiner, Adv. Mater., 2003, 15, 959970.

6 E. Loste, R. M. Wilson and R. Seshadri, J. Cryst. Growth, 2003, 254, 206-218.

7 Y. Politi, D. R. Batchelor and P. Zaslansky, Chem. Mater., 2009, 22, 161-166.

8 D. Gebauer, H. Cölfen and A. Verch, Adv. Mater., 2009, 21, 435-439.

9 D. Tobler, J. Rodriguez, J. D. Blanco and K. Dideriksen, Adv. Funct. Mater., 2015, 25, 3081-3090.

10 D. Gebauer, P. N. Gunawidjaja and J. Y. Ko, Angew. Chem., 2010, 122, 9073-9075.

11 J. J. J. M. Donners, B. R. Heywood and E. W. Meijer, Chem.Eur. J., 2002, 8, 2561-2567.

12 B. Guillemet, M. Faatz and F. Gröhn, Langmuir, 2006, 22, 1875-1879.

13 J. Bolze, B. Peng and N. Dingenouts, Langmuir, 2002, 18, 8364-8369.

14 Y. Tanaka and K. Naka, Polym. J., 2010, 42, 676-683.

15 A. Carino, A. Testino, M. R. Andalibi, F. Pilger, P. Bowen and C. Ludwig, Cryst. Growth Des., 2017, 17, 2006-2015.

16 A. E. Nielsen, Kinetics of Precipitation, Oxford: Pergamon Press, 1964.

17 A. Testino, V. Buscaglia and M. T. Buscaglia, Chem. Mater., 2005, 17, 5346-5356.

18 S. C. Huang, K. Naka and Y. Chujo, Langmuir, 2007, 23, 12086-12095.

19 X. Wang, R. Kong and X. Pan, J. Phys. Chem. B, 2009, 113, 8975-8982.

20 J. Rieger, T. Frechen, G. Cox, et al., Faraday Discuss., 2007, 136, 265-277.

21 Y. Y. Kim, J. D. Carloni and B. Demarchi, Nat. Mater., 2016, 15, 903-910.

22 D. J. Tobler, B. J. D. Rodriguez and H. O. Sørensen, Cryst. Growth Des., 2016, 16, 4500-4508.

23 H. W. Wang, L. L. Daemen and M. C. Cheshire, Chem. Commun., 2017, 53, 2942-2945.

24 M. P. Schmidt, A. J. Ilott and B. L. Phillips, Cryst. Growth Des., 2014, 14, 938-951.

25 N. Koga, Y. Nakagoe and H. Tanaka, Thermochim. Acta, 1998, 318, 239-244.

26 C. Rodriguez-Navarro, K. Kudłacz and Ö. Cizer, CrystEngComm, 2015, 17, 58-72.

27 R. Demichelis, P. Raiteri, J. D. Gale, D. Quigley and D. Gebauer, Nat. Commun., 2011, 2, 590. 
28 S. E. Wolf, L. Muller, R. Barrea, C. J. Kampf, J. Leiterer, U. Panne, T. Hoffmann, F. Emmerling and W. Tremel, Nanoscale, 2011, 3, 1158-1165.

29 L. Balogh and D. A. Tomalia, J. Am. Chem. Soc., 1998, 120, 7355-7356.

30 J. D. Rodriguez-Blanco, S. Shaw and L. G. Benning, Nanoscale, 2011, 3, 265-271.

31 D. C. Green, J. Ihli, Y. Y. Kim, et al., Cryst. Growth Des., 2016, 16, 5174-5183.
32 J. Wang, C. Q. Li, S. Y. Zhang, F. Sun and T. J. Ge, Chin. Chem. Lett., 2008, 19, 43-46.

33 M. F. Ottaviani, S. Bossmann and N. J. Turro, J. Am. Chem. Soc., 1994, 116, 661-671.

34 D. A. Tomalia, A. M. Naylor and W. A. Goddard, Angew. Chem., Int. Ed., 1990, 29, 138-175.

35 Y. Kojima, A. Kawanobe, T. Yasue, Y. Arai and J. Ceram, J. Ceram. Soc. Jpn., 1993, 101, 1145-1152. 